\title{
Human Resource Management in Selected District Hospitals of Bangladesh- A Cross Sectional Study.
}

\author{
Banik S ${ }^{1}$, Rubby M G ${ }^{2}$, Debnath K C ${ }^{3}$, Shaon F T U ${ }^{4}$, Tanaya F P ${ }^{5}$, Tuni C B ${ }^{6}$
}

Received: 30.09.2017

Accepted: 28.11.2017

\section{Abstract:}

Human resource management (HRM) is fundamental of any organization because of its utility. $A$ cross-sectional was conducted from January to December, 2016 in two district hospitals named General Hospital, Munshiganj and 100 Bedded District Hospital, Narsingdi with the objective to assess the status of HRM. Purposively 144 hospital staffs were selected and interviewed by using semi-structured questionnaire and record review. The collected data were processed and analyzed meticulously with the help of SPSS (Version 21) software on the basis of different variables. The study revealed that the mean age was $36.6 \pm 1.8$ years, $71.5 \%$ were clinical and nursing personnel, other category of respondents were support services and other personnel (22.2\%), administrative personnel (6.3 \%).Most (96.5\%) of the respondents were recruited by Government, after recruitment $52.1 \%$ hospital staffs mentioned scope of training facilities either work-based or instruction based exists in workplace, $63.9 \%$ needed to be trained, $80.6 \%$ wished further career plan. Working environment found friendly by $39.6 \%$ hospital staffs, where as average found by $50.0 \%$. The recommendations for further improvement of HRM of their workplace was to increase training facilities by $31.9 \%$, other recommendations were to increase manpower, improvement of monitoring and supervision. From this study some effort in the training, increase of manpower, performance appraisal can ensure better quality of service at district hospitals.

Key words: Human Resource Management, Organization, District Hospital.

1. Dr. Shovon Banik, Consultant, Dentolife Dental Care, South Banashree, Dhaka.

2. Dr. Md. Golam Rubby, Associate Professor \& Head, Department of Orthodontics, Mandy Dental College, Dhaka.

3. Dr. Kala Chand Debnath, Dental Surgeon, Dentolife Dental Care, South Banashree, Dhaka.

4. Dr. Farzana Tamanna Ummey Shaon, Dental Surgeon, Rimi Dental Care, Motijheel,Dhaka.

5. Dr. Farhana Parveen Tanaya, MPH Student, Session 2017-1018, NIPSOM, Mohakhali, Dhaka.

6. Chidananda Banik Tuni, LLB (UK), LLM (UK)

Correspondence : Dr. Shovon Banik, Phone: 01718267442, E-mail: shovon.banik@gmail.com 


\section{Introduction:}

Human resource management (HRM) is a system, a philosophy, policy and practices that can influence individuals working in an organization ${ }^{[1]}$. An effective and competitive human resource is the key strength of organizations in facing the challenges of business today. Successful organizations recognize the significance of human element in the organizational success and emphasize on their development, satisfaction, commitment and motivation in order to attain desired objectives ${ }^{[2]}$. The importance of HRM in healthcare lies in the fact that a well-managed human resource department is vital for the delivery of efficient and quality healthcare services. In developed countries the human resource managers have identified the challenges they face and have developed different strategies to overcome these challenges ${ }^{[3]}$. But developing countries like Bangladesh, India and Pakistan are still facing many challenges in implementing human resource management practices in healthcare sector ${ }^{[4]}$.Despite rising attention to delivery of healthcare services in Bangladesh, little attention has been paid to the role of human resource management which can transform health workers into a productive, motivated, and supported workforce capable of improving healthcare services and saving lives. Lack of attention towards the role human resource management in the health sector is a key factor standing between success and failure in Bangladesh $^{[5]}$. District hospitals are very important place for health facilities to care and cure of the patients; it is the place where secondary health care is given. The skillful use of human resources, proper methods of selection training and motivation, division of responsibilities; distribution of roles, incentives for better works, opportunities for promotion and professional advancement, effective design of "Health team" could contribute to efficiency of health service delivery. The major components of HRM covers job design, recruitment and selection, capacity building, job facilities and environment. The aim of the study was to assess the status of human resource management in selected district hospitals of Bangladesh which includes the overall recruitment process, capacity building opportunities of hospital staffs, the working environment and the organizational activities for retaining employees. This study was conducted with a hope and expectation to know the problems and constraints in the field of HRM practices in the selected district hospitals so as to facilitate health activities of selected areas by upgrading the quality of services.

\section{Materials and methods:}

The descriptive type of cross sectional study was conducted in two District Level Govt. Hospitals of Bangladesh, one was General Hospital, Munshiganj and the other one was 100 Bedded District Hospital, Narsingdi for the duration of one year from January to December, 2016. Data were collected from 144 hospital staffs (administrative, clinical and nursing personnel, support services and other personnel) by face to face interview administered questionnaire and record review. The study was approved by the Institutional Review Board of National Institute of Preventive \& Social Medicine (NIPSOM) and official permission for data collection was obtained from the Civil Surgeons of District Hospitals. After developing the questionnaire was pre tested for necessary modification and finalization. Then the master tabulation sheet was prepared after proper checking, verifying and editing as per specific objectives and key variables. Analysis of data was finally done with Statistical Package for Social Science (SPSS) software (version 21 ) of computer on the basis of difference variables. Then the data presentation was perfectly done by MS Word and MS Excel. Verbal consent was taken from the respondents. Confidentiality and anonymity of the respondents was maintained.

\section{Results:}

Table 1: Socio demographic characteristics of the respondents (hospital staffs).

\begin{tabular}{|l|c|c|c|}
\hline \multicolumn{1}{|l|}{ Socio demographic characteristics } & Frequency & Percentage \\
\hline \multirow{4}{*}{ Age group (in years ) } & $19-25$ & 7 & 4.9 \\
\cline { 2 - 4 } & $26-35$ & 56 & 38.9 \\
\cline { 2 - 4 } & $36-45$ & 78 & 54.2 \\
\cline { 2 - 4 } & $46-55$ & 3 & 2.1 \\
\cline { 2 - 4 } $\begin{array}{l}\text { Category of the } \\
\text { respondents }\end{array}$ & $\begin{array}{c}\text { Mean ( } \pm \text { SD) } \\
\text { Administrative } \\
\text { personnel }\end{array}$ & 9 & 6.3 \\
\cline { 2 - 4 } & $\begin{array}{c}\text { Clinical and Nursing } \\
\text { personnel }\end{array}$ & 103 & 71.5 \\
\cline { 2 - 4 } & $\begin{array}{c}\text { Support services and } \\
\text { other personnel }\end{array}$ & 32 & 22.2 \\
\hline Sex & Male & 74 & 51.4 \\
\cline { 2 - 4 } & Female & 70 & 48.6 \\
\hline
\end{tabular}

Table 1 revealed that out of $144(100.0 \%)$ respondents (hospital staffs) the mean age was $36.6 \pm 1.8$ years and the category of the respondents was clinical and nursing personnel $71.5 \%$, support services and other personnel $22.2 \%$ and $6.3 \%$ was administrative personnel, 74 (51.4\%) were male and $70(48.6 \%)$ were female. 
Table 2 : Distribution of the respondents (hospital staffs) by their recruitment procedure related information.

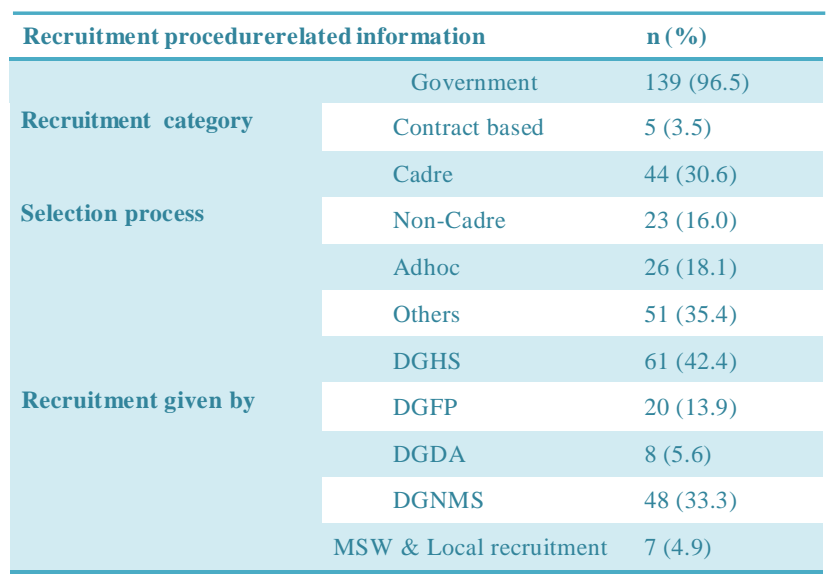

Table 2 shows the recruitment category 139 (96.5\%) were Government, 5 (3.5\%) recruited as contract based, the selection process was Cadre, Non-Cadre, Adhoc and others 44 (30.6\%), 23 (16.0\%), 26 $(18.1 \%)$ and 51 (35.4\%) respectively. Among 144 (100.0\%) hospital staffs 61 (42.4\%) were recruited by DGHS, 48 (33.3\%) recruited by DGNMS.

Table 3 : Distribution of the respondents (hospital staffs) by their capacity building facilities related information.

\begin{tabular}{|l|l|l|}
\hline \multicolumn{2}{|l|}{ Capacity building facilities related information } & $\mathbf{n}(\%)$ \\
\hline $\begin{array}{l}\text { Scope for training (either } \\
\text { work-based or instruction based) }\end{array}$ & Exists & $75(52.1)$ \\
\cline { 2 - 3 } & Not exists & $69(47.9)$ \\
\hline \multirow{2}{*}{$\begin{array}{l}\text { Demand for training } \\
\text { opportunities }\end{array}$} & Asked & $92(63.9)$ \\
\hline \multirow{2}{*}{ Job training } & Not asked & $52(36.1)$ \\
\hline \multirow{3}{*}{ Wish to career plan } & Received & $96(66.7)$ \\
\cline { 2 - 3 } & Not received & $48(33.3)$ \\
\hline
\end{tabular}

Table 3 shows that 75 (52.1\%) hospital staffs mentioned scope of training facilities either work-based or instruction based exists in workplace, $92(63.9 \%)$ had demand for training opportunities, $116(80.6 \%)$ were interested to career plan.
Figure 1 : Distribution of the respondents (hospital staffs) by their opinion about working environment.

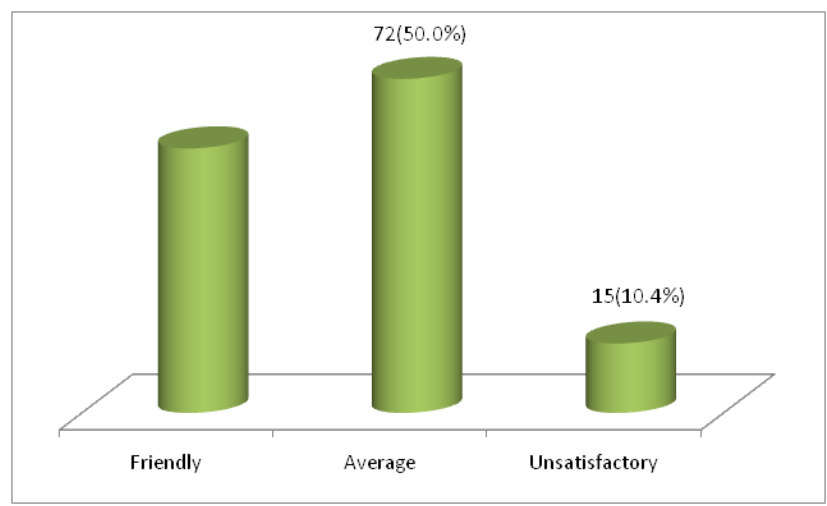

Figure 1 shows that out of 144 respondents 72 $(50.0 \%)$ gave their opinion about working environment is average, 57 (39.6\%) and 15 (10.4\%) mentioned friendly and unsatisfactory respectively.

Table 4 : Distribution of the respondents (hospital staffs) by their organizational activities for HRM related information. [ $n=144]$

\begin{tabular}{|c|c|c|}
\hline \multicolumn{2}{|c|}{ Organizational activities for HRM related information } & \multirow{2}{*}{$\begin{array}{l}\mathbf{n}(\%) \\
85(59.0)\end{array}$} \\
\hline \multirow{4}{*}{$\begin{array}{l}\text { Process of performance } \\
\text { evaluation }\end{array}$} & $\begin{array}{c}\text { Annual Confidential Report } \\
\text { (ACR) }\end{array}$ & \\
\hline & $\begin{array}{c}\text { Performance appraisal forms } \\
\text { and reports }\end{array}$ & $22(15.3)$ \\
\hline & Self-assessment tool & $11(7.6)$ \\
\hline & Others & $26(18.0)$ \\
\hline \multirow{3}{*}{$\begin{array}{l}\text { Frequency of performance } \\
\text { appraisal }\end{array}$} & Yearly & $77(53.5)$ \\
\hline & Monthly & $5(3.5)$ \\
\hline & Incidentally & $62(43.0)$ \\
\hline \multirow{2}{*}{$\begin{array}{l}\text { Scope for participation in } \\
\text { planning / decision making }\end{array}$} & Participated & $50(34.7)$ \\
\hline & Never participated & $94(65.3)$ \\
\hline \multirow[t]{3}{*}{ Motivational activities } & Bonus & $72(59.3)$ \\
\hline & Special leave & $16(13.1)$ \\
\hline & Training \&others & $34(23.6)$ \\
\hline \multirow[t]{2}{*}{ Existence of punishment } & Exists & $135(93.8)$ \\
\hline & Not exists & $9(6.3)$ \\
\hline \multirow[t]{4}{*}{ Type of punishment } & Verbal Reprimand & $53(36.8)$ \\
\hline & Suspension & 69(47.9) \\
\hline & Penalty & 11(7.6) \\
\hline & Others & 11(7.6) \\
\hline
\end{tabular}

Table 4 shows the organizational activities for HRM, here the process of performance evaluation was Annual Confidential Report (ACR), Performance appraisal forms and reports mentioned by $85(59.0 \%)$, $22(15.3 \%)$ respectively. The frequency of performance appraisal mentioned by 77 (53.5\%), 62 
(43.0\%) yearly, incidentally respectively; 50 (34.7\%) had scope to participate in planning / decision making, where as $94(65.3 \%)$ never participated in planning / decision making activities. The motivational activities for HRM was bonus, training and others, special leave mentioned by $72(59.3 \%), 34$ (23.6\%) and $16(13.1 \%)$ respectively;135 (93.8\%) mentioned about existence of punishment and the type of punishment mentioned suspension, verbal reprimand by $69(47.9 \%), 53(36.8 \%)$ respectively.

Table 5 : Status of human resource in district hospitals

\begin{tabular}{|l|l|l|l|}
\hline Class & Sanctioned & Filled & Vacant \\
\hline Class I & $51(100.0 \%)$ & $39(76.5 \%)$ & $12(23.5 \%)$ \\
\hline Class II & $39(100.0 \%)$ & $35(89.7 \%)$ & $4(10.3 \%)$ \\
\hline Class III & $71(100.0 \%)$ & $38(53.5 \%)$ & $33(46.5 \%)$ \\
\hline Class IV & $79(100.0 \%)$ & $53(67.1 \%)$ & $26(32.9 \%)$ \\
\hline Total & $268(100.0 \%)$ & $165(61.5 \%)$ & $103(38.5 \%)$ \\
\hline
\end{tabular}

Table 5 shows that in district hospitals total sanctioned post including all class was 268 (100.0\%), where $165(61.5 \%)$ was filled and $103(38.5 \%)$ was vacant. Maximum vacancy $33(46.5 \%)$ was observed in Class III, where the sanctioned post was $71(100.0 \%)$.

Figure 2 : Distribution of the respondents (hospital staffs) by their recommendations to improve HRM of the workplace. [ $n=144]$

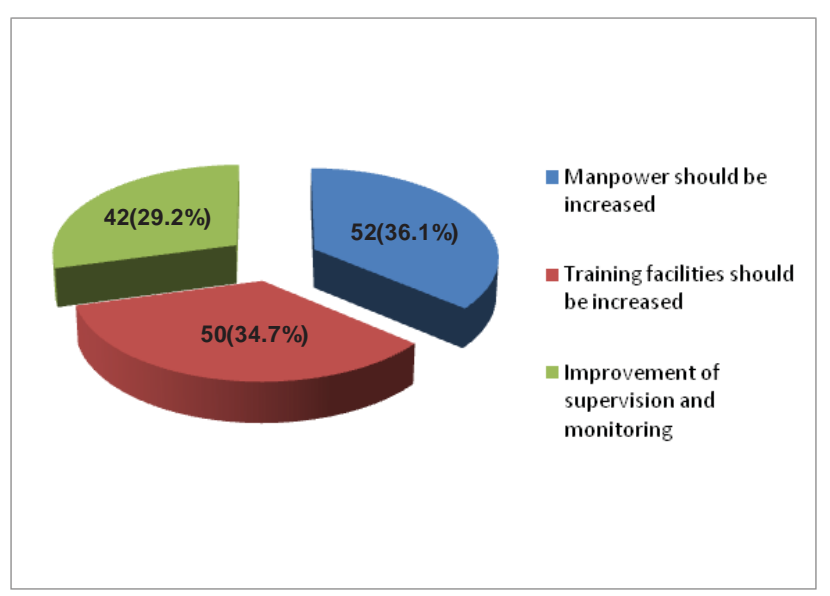

Figure 2 shows out of 144 hospital staffs 52 (36.1\%) suggested to increase manpower, 50 (34.7\%) suggested to increase training facilities, 42 (29.2\%) suggested for the improvement in monitoring and supervision improve HRM of the workplace.

\section{Discussion:}

Within many healthcare systems worldwide, increased attention is being focused on human resources management (HRM). Specifically, human resources are one of three principle health system inputs, with the other two major inputs being physical capital and consumables. In the present study 144 human resources were selected from two different district hospitals in Bangladesh to assess the status of human resource management and the study result revealed that the mean age was $36.6 \pm 1.8$ years ; more than half $(54.2 \%)$ of the respondents age were in between 36-45 years, which was consistent with the study conducted by Barman N, $2014{ }^{[9]}$. Majorities $(51.40 \%)$ of the respondents were male; among the 144 human resources participated in the study majority $(71.9 \%)$ were clinical and nursing personnel, only (6.3\%) were administrative personnel, which was not consistent with the study ${ }^{[6]}$ which found most $(74.20 \%)$ of the respondents were female and the majority $(67.0 \%)$ were from management background. This study found only $3.5 \%$ of respondents were recruited on contractual basis which is not consistent with the study ${ }^{[7]}$ which found in district hospital $30.0 \%$ of respondents were recruited on the basis of contract. In the selection process Cadre, Non-Cadre, Adhoc and others were $30.6 \%$, $16.0 \%, 18.1 \%$ and $35.4 \%$ respectively. Though all the hospital staffs are recruited through Ministry of Health and Family Welfare $42.4 \%$ respondents were recruited by Directorate General of Health Services (DGHS), 33.3\% recruited by Directorate General of Nursing and Midwifery Services (DGNMS), only 4.9 $\%$ were placed locally either by Civil Surgeon or by Ministry of Social Welfare (MSW). Regarding capacity building facilities in workplace present study found more than half $(52.10 \%)$ mentioned the scope of training facilities exists in their workplace which was inconsistent with study conducted by Aftabuzzaman M.2012 ${ }^{[7]}$, which found most of the respondents $(82.3 \%)$ were dissatisfied about their scope of training. Majority $(63.90 \%)$ mentioned that they need training which was consistent with the study conducted by Montesinos JL.2013 ${ }^{[8]}$, where $58.40 \%$ need further training. The study conducted by Jardali $F^{[6]}$ found $54.6 \%$ of respondents reported the need for career plan whereas the present study suggests that most $(80.60 \%)$ of the enrolled hospital staffs wish career plan either higher academic education or promotion, Majority $(66.7 \%)$ received job training 
after recruitment. On the other hand $39.10 \%$ of respondents neither got any on job training nor interested while $60.90 \%$ of respondents were demanding further training. This study assessed that less than half $39.6 \%$ of enrolled staffs from the two district hospitals suggested their workplace environment as friendly, half $(50.0 \%)$ suggested as average. About the presence of punishment for any indiscipline most of the respondents $93.7 \%$ agreed and $6.3 \%$ refused; the type of punishment $47.9 \%$ informed about suspension, verbal reprimand $(36.8 \%)$, penalty (7.6\%). Other organizational activities for HRM showed the present study motivational activities, bonus mentioned by $59.3 \%$, training, special leave. Present study found majority $(65.3 \%)$ never participated or didn't got the scope to participate in planning / decision making. In district hospitals the filled post including all class found $61.5 \%$ and maximum vacancy $46.5 \%$ observed in Class III. Regarding recommendations to improve HRM more that one third $(36.1 \%)$ recommended to increase manpower and other recommendations were to increase training facilities, to improve monitoring and supervision.

\section{Conclusion:}

Based on the findings of the present study, it can be concluded that majorities of the respondents were satisfied in scopes of training, received training, asked for training and were interested for career plan which is a positive sign in capacity building facilities of an organization. There was average working environment for the employee. A congenial working environment was present between colleagues. On the other hand various type of punishment process was observed like verbal reprimand, suspension, penalty etc. Performance appraisals of the employees are done annually by ACR. Some employees participate in decision making but the percentage was poor. Various motivational activities like bonus, special leave, training, good working environment exists to maintain the effective workforce of hospital. Due to the vacant post the organizational activities can hamper, which has been reflected in the recommendation of the hospital staffs. The study suggests effective and efficient human resource management practice in district hospital to ensure optimum and quality healthcare delivery service. However specific problems identified by different stakeholders need to be critically appraised by the authority to improve the HRM further.

\section{References :}

1. Nasiripour A, Afshar K M, Izadi A. Effect of Different HRM Policies on Potential of employee Productivity, Research Journal of Recent Sciences, 2012; 1(16), 45-54.

2. Bahuguna PC, Kumari P, Srivastava S.K. Changing Face of Human Resource Management: A Strategic Partner in Business, Management and Labor Studies, 2009; 39(4), 563-581

3. Singh G, Singh A, Singh A. Perception of Departmental Heads and Chief Executives towards Hospital HR Management Issues: A Comparison of Public and Private Hospitals in India, International Journal of Human Resource Studies,2012; 2(3)

4. Naz A, Daraz U, Khan T, Khan W, Hussain M. An Analytical Study of Patients Health Problems in Public Hospitals of Khyber Pakhtunkhwa Pakistan, International Journal of Business and Social Science, 2012; 3(5)

5. Jeffrey H, Michael K, Nazmul C, Karthik M. " The Challenges of implementing Human Resource Management Practices in Developing Countries." World Bank Economic Review:2005; 10-43.

6. Jardali F, Tchaghchagian V, Jamal D. Assessment of human resources management practices in Lebanese hospitals. Hum Resour Health,2009; 7:84

7. Aftabuzzaman M. Human resource management in a district hospital [dissertation], 2012; NIPSOM 1-70

8. Montesions JL. Psychological study about the consequences of work in hospital nurses as human resource management. Revista Latino-American de Enfermagem, 2013; 21:127-145.

9. Barman N. Human resource management in district hospitals of Bangladesh [thesis], 2014; NIPSOM 1-92. 